\title{
Herbal Medicine for the Treatment of Viral Hepatitis B and C: A Systematic Review of Randomized Controlled Trials
}

\author{
Seung-mo Kim, Yu-ri Lee, Na-kyung Cho, Hong-sik Choi, Kyung-soon Kim \\ Dept. of Korean Internal Medicine of Hepatology, College of Korean Medicine, Daegu Haany University
}

\section{Herbal Medicine for the Treatment of Viral Hepatitis B and C: A Systematic Review of Randomized Controlled Trials}

\author{
Seung-mo Kim, Yu-ri Lee, Na-kyung Cho, Hong-sik Choi, Kyung-soon Kim
}

Dept. of Korean Internal Medicine of Hepatology, College of Korean Medicine, Daegu Haany University

\begin{abstract}
The aim of this study was to perform a systematic review and meta-analysis of randomized controlled trials (RCTs) that applied herbal medicine to treat viral hepatitis $\mathrm{B}$ and $\mathrm{C}$ in order to determine the therapeutic efficacy of herbal medicine.

EMBASE, Pubmed, NDSL, KMBASE, KISS, KISTI, Koreamed, Koreantk, and Oasis databases were searched to identify RCTs. The selected studies were assessed by the Cochrane group's risk of bias tool.

A total of 15 RCTs were selected, and the hepatitis B virus (HBV) DNA reduction was significantly higher in patients treated with herbal medicine combined with Western medicine than in patients treated with herbal medicine. Herbal medicine combined with Western medicine was also superior to Western medicine alone in achieving hepatitis B e-antigen ( $\mathrm{HBeAg}$ ) and alanine aminotransferase [ALT] reduction. Only herbal medicine alone was not superior to Western medicine treatments in achieving HBV DNA, HBeAg, and ALT reduction.
\end{abstract}

Key words: herbal medicine, viral hepatitis, systematic review, meta-analysis

\section{Introduction}

Hepatitis viruses (Type A, B, C, D, E) cause acute and chronic liver inflammation and they lead

· 투고일 : 2021.06.08, 심사일: 2021.09.29, 게재확정일: 2021.09.29

- Corresponding author: Kyung-soon Kim Dept. of Korean Internal Medicine of Hepatology, College of Korean Medicine, Daegu Haany University, 136, Sincheondong-ro, Suseong-gu, Daegu, Korea TEL: 82-770-2082 FAX: 82-770-2055 E-mail:occ@dhu.ac.kr

- This work was supported by the National Research Foundation of Korea (NRF) grant funded by the Korean government (MSIT) (No. 2018R1A5A2025272). to asymptomatic inactivated infection, to fatal acute hepatitis or fulminant hepatitis. They differ significantly in biology, disease progress and therapy options².

Globally in 2015, hepatic viruses induced hepatitis caused 1.34 million deaths primarily from cirrhosis and hepatocellular carcinoma secondary to chronic hepatitis $B$ virus and hepatitis $C$ virus infections ${ }^{3}$. Despite antivirus B treatment, it is difficult to expect complete eradication, so it is important to maintain the viral response for a long time. $e^{4}$ Hepatitis C mostly transitions to chronic hepatitis without obvious clinical symptoms, which results in low 
Herbal Medicine for the Treatment of Viral Hepatitis B and C: A Systematic Review of Randomized Controlled Trials

recognition and delayed diagnosis, increasing the economic burden of the disease ${ }^{5}$. Thus, the treatment of patients with chronic hepatitis via complementary and alternative medicine for improvement in liver function and symptoms is increasing in popularity ${ }^{6}$.

Treatment of viral hepatitis falls under the following categories of Korean medicine: jaundice, aggregation-accumulation, distention and fullness? .

Although studies on viral hepatitis treatment have been published both inside and outside of Korea, there are a limited number of studies related to viral hepatitis treatment using herbal medicine monotherapy or combination therapy consisting of herbal and Western medicine. In addition, there are no systematic reviews of the clinical trials. Thus, this study aimed to review clinical trials that investigated the therapeutic effect of herbal medicine on viral hepatitis, and evaluate and provide evidence of the efficacy of this treatment via a meta-analysis.

\section{Materials and methods}

\section{Participants}

Herbal medicine articles published in and outside of Korea that investigated the therapeutic effect of herbal medicine in patients with viral hepatitis were included. The systematic review was performed using the participants, intervention, comparison, outcome, and study design (PICO-SD) format ${ }^{8}$. In vivoand in vitro studies of non-human subjects, unoriginal studies, and studies published as abstracts only were excluded.

1) Participants : Patients with viral hepatitis (recorded characteristics including patient age, patient sex, and hepatitis B or C infection)

2) Intervention : Herbal medicine treatment

3) Comparison : Control groups not restricted
4) Outcome : Notrestricted

5) Study design : Randomized controlled trial (RCT)

\section{Methods}

1) Database selection and literature search

For studies published in Korea, literature searches were performed using the following Korean databases: the National Digital Science Library (http://www. ndsl.kr), Korean Medical Database (http://kmbase. medric.or.kr), Korean Studies Information Service System (http://kiss.kstudy.com), Korea Institute of Science and Technology Information Society (http://society.kisti.re.kr), KoreaMed (http://www. koreamed.org), Korean Traditional Knowledge Portal (http://www.koreantk.com), and Korea Institute of Oriental Medicine (http://oasis.kiom.re.kr). The search terms were '간염' or '바이러스성간염, '한약' or '한의학', '임상시험', 'hepatitis' or 'viral hepatitis,' 'herbal medicine,' and 'randomized controlled trials.'

For studies published outside of Korea, literature searches were performed using PubMed (http:// www.ncbi.nlm.nih.gov/pubmed/) and EMBASE (http:// www.embase.com). The search terms were 'hepatitis' or 'viral hepatitis,' 'herbal medicine' or 'traditional Chinese medicine, and 'randomized controlled trial.'

2) Study selection

Two researchers (LYR and CNK) independently performed the literature search and study selection. The identified studies were collected and duplicates were excluded. According to the inclusion and exclusion criteria, the studies were initially selected by examining their titles and abstracts. The full texts of the studies were then evaluated to select RCTs that investigated the use of herbal medicine for the treatment of viral hepatitis. In cases of disagreement between the two researchers, a third 
researcher (KKS) intervened and a consensus was reached by majority vote.

The literature search was conducted from August 1 to August 3, 2018. Studies published up to July 2018 were included, with no restrictions on language (Fig. 1).

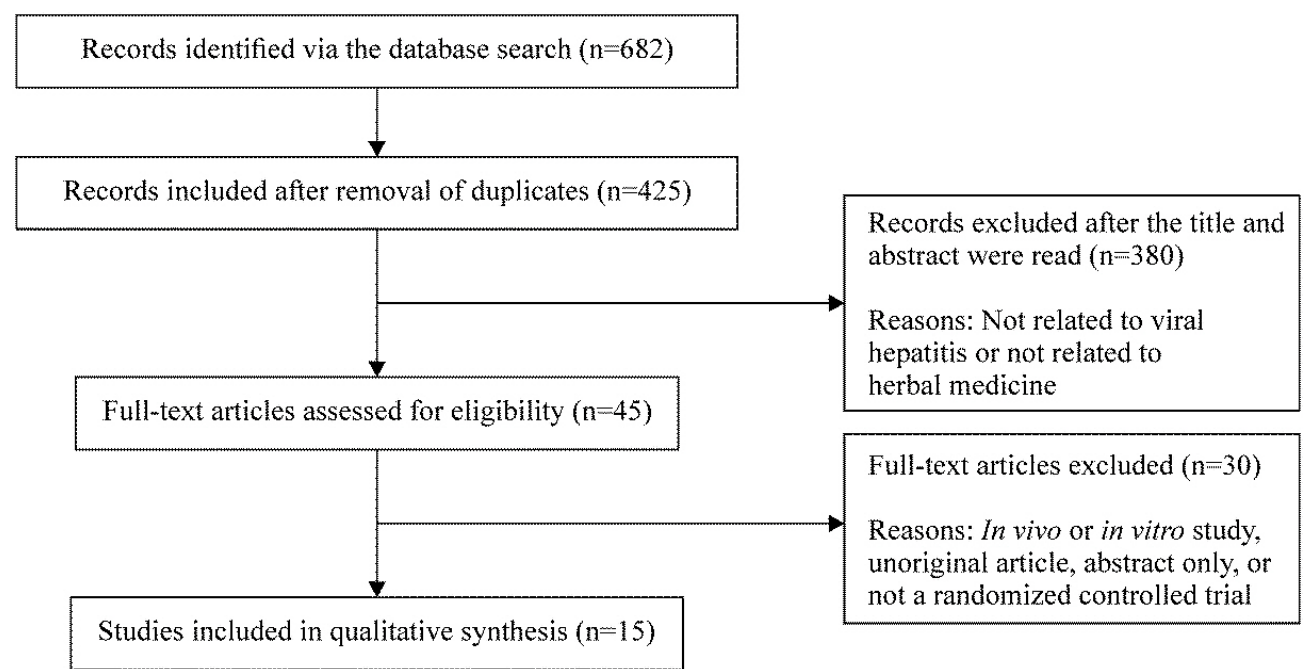

Fig. 1. Flow diagram of the selection process.

\section{3) Data analysis}

After two reviewers (LYR, CNK) reviewed the full text of the selected studies, data regarding the publication year, number of study participants, method and duration of treatment in intervention and control groups, measurement instruments, treatment outcomes, and reports of adverse events were extracted from each study. Based on the extracted data, the characteristics of each study were reviewed.

4) Risk of bias assessment

The Cochrane Risk of Bias (RoB) tool was used for the risk of bias assessment, as only RCTs were reviewed in this study ${ }^{9}$. This tool includes seven domains of assessment: random sequence generation, allocation concealment, blinding of participants and personnel, blinding of the outcome assessor, handling incomplete outcome data, selective outcome reporting, and other sources of bias that threaten the validity of the study findings. For the detailed criteria of each domain, the National Evidence-Based Healthcare Collaborating Agency guidelines for systematic reviews were used ${ }^{9}$.

5) Publication bias

Publication bias is a type of reporting bias that occurs when there is an association between the possibility of publishing and the statistical significance of the study results. It is generally represented by a funnel plot, and Egger's regression test was performed as a statistical test for publication bias.

6) Meta-analysis

Statistical analysis of the studies included in the systematic review was performed using the Cochrane Collaboration's RevMan (Review Manager) version 5.3. The odds ratio (OR) and a two-sided 
Herbal Medicine for the Treatment of Viral Hepatitis B and C: A Systematic Review of Randomized Controlled Trials

95\% confidence interval (CI) were used for binary outcome data, while the mean difference (MD) and a $95 \%$ CI were used to measure the effect size for continuous outcome data. After assessing heterogeneity using Higgin's $\mathrm{I}^{2}$, twomodels, fixed-effects (in $\mathrm{I}^{2}=0 \%$ or not applicable) and random-effects (in $\mathrm{I}^{2} \neq 0 \%$ ), were used to combine the summary statistics.

\section{Results}

\section{Data selection}

Literature search using a total of nine databases from August 1 to August 3, 2018 identified a total of 425 studies. After reviewing the titles and abstracts of these studies, 380 studies not related to viral hepatitis and herbal medicine were excluded. The 45 studies that were initially selected were read in detail, and $15^{10-24}$ studies were finally selected (Fig. 1).

\section{Data analysis}

Of the selected studies, 11 were conducted in China, three were conducted in Taiwan, and one was conducted in Australia. Participants, treatment methods, outcomes of interventions, and control groups were assessed (Table 1).

Table 1. Summary of the Randomized Controlled Trials Included in This Study

\begin{tabular}{|c|c|c|c|c|c|c|}
\hline $\begin{array}{l}\text { Author } \\
\text { (year) }\end{array}$ & Disease & Sample size & $\begin{array}{l}\text { Treatment } \\
\text { period }\end{array}$ & Intervention & Control & Result \\
\hline $\begin{array}{l}\text { Batey } \\
(1998)\end{array}$ & $\begin{array}{l}\text { Chronic } \\
\text { hepatitis C }\end{array}$ & $\begin{array}{l}\text { Total }=40 \\
\text { Cases }=20 \\
\text { Controls }=20\end{array}$ & 24 weeks & $\begin{array}{l}\mathrm{CH}-100 \\
\text { (19 herb formula, } \\
\text { three times daily) }\end{array}$ & $\begin{array}{l}\text { Placebo tablets } \\
\text { (three times daily) }\end{array}$ & $\begin{array}{l}\text { 1. } \text { HCV clearance } \\
\text { Cases }=0 / 20 \\
\text { Controls }=0 / 20 \\
\text { 2. ALT } \\
\text { Cases }=82 \pm 54^{*} \\
\text { Controls }=102 \pm 58\end{array}$ \\
\hline $\begin{array}{l}\text { Chen } \\
(2000)\end{array}$ & $\begin{array}{l}\text { Chronic } \\
\text { hepatitis B }\end{array}$ & $\begin{array}{l}\text { Total }=94 \\
\text { Cases }=45 \\
\text { Controls }=49\end{array}$ & 12 weeks & $\begin{array}{l}\text { Kurorinone } \\
\text { ( } 400 \mathrm{mg} \text { intramuscular } \\
\text { injection daily) }\end{array}$ & $\begin{array}{l}\text { Interferon-a2a } \\
\text { ( } 3 \text { million units } \\
\text { subcutaneous } \\
\text { injection daily for } \\
1 \text { month and every } \\
\text { other day for } \\
2 \text { months) }\end{array}$ & $\begin{array}{l}\text { 1. HBV DNA loss (mild group) } \\
\text { Cases }=11 / 20 \\
\text { Controls }=14 / 21 \\
\text { 2. HBeAgloss (mild group) } \\
\text { Cases }=10 / 20 \\
\text { Controls }=12 / 19 \\
\text { 3. ALT (mild group) } \\
\text { Cases }=41.3 \pm 20.6^{* *} \\
\text { Controls }=45.7 \pm 28.6^{* *} \\
\text { 4. HBV D NA loss } \\
\text { (moderate group) } \\
\text { Cases }=6 / 11 \\
\text { Controls }=9 / 13 \\
\text { 5. HBeAg loss (moderate group) } \\
\text { Cases }=5 / 9 \\
\text { Control }=6 / 10 \\
\text { 6. ALT (moderate group) } \\
\text { Cases }=52.4 \pm 25.6^{* *} \\
\text { Controls }=60.4 \pm 28.3^{* *}\end{array}$ \\
\hline
\end{tabular}




\begin{tabular}{|c|c|c|c|c|c|c|}
\hline $\begin{array}{l}\text { Chen } \\
\text { (2005) }\end{array}$ & $\begin{array}{l}\text { Chronic } \\
\text { hepatitis B }\end{array}$ & $\begin{array}{l}\text { Total }=85 \\
\text { Cases }=50 \\
\text { Controls }=35\end{array}$ & 24 weeks & $\begin{array}{l}\text { He Jie Tang } \\
\text { (nine herb formula, } \\
\text { once daily) }\end{array}$ & $\begin{array}{l}\text { Oxymatrine tablets } \\
\text { (vitamin B.C.E. } \\
\text { two tablets three } \\
\text { times daily) }\end{array}$ & $\begin{array}{l}\text { 1. } \text { HBV DNA loss } \\
\text { Cases }=0 / 50 \\
\text { Controls }=0 / 35 \\
\text { 2. } \text { HBeAg loss } \\
\text { Cases }=2 / 50 \\
\text { Controls }=2 / 35 \\
\text { 3. ALT } \\
\text { Cases }=33.26 \pm 9.35^{* *} \\
\text { Controls }=30.86 \pm 8.95^{* *}\end{array}$ \\
\hline $\begin{array}{l}\text { Chen } \\
\text { (2017) }\end{array}$ & $\begin{array}{l}\text { Chronic } \\
\text { hepatitis C }\end{array}$ & $\begin{array}{l}\text { Total }=60 \\
\text { Cases }=29 \\
\text { Controls }=31\end{array}$ & 12 weeks & $\begin{array}{l}\text { Rong-Yang-Jyh-Gan-Tang } \\
\text { (20 tablets three times daily) }\end{array}$ & $\begin{array}{l}\text { Placebo ( } 20 \text { tablets } \\
\text { three times daily) }\end{array}$ & none \\
\hline $\begin{array}{l}\mathrm{He} \\
(2013)\end{array}$ & $\begin{array}{l}\text { Chronic } \\
\text { hepatitis B }\end{array}$ & $\begin{array}{l}\text { Total }=267 \\
\text { Cases }=174 \\
\text { Controls }=93\end{array}$ & 52 weeks & $\begin{array}{l}\text { Chinese Herbal Formula } \\
\text { (14 herb formula, } \\
\text { once daily) }\end{array}$ & $\begin{array}{l}\text { Placebo } \\
\text { (once daily) }\end{array}$ & $\begin{array}{l}\text { 1. HBV DNA loss } \\
\text { Cases }=1 / 200 \\
\text { Controls }=1 / 100\end{array}$ \\
\hline $\begin{array}{l}\text { Lee } \\
\text { (2013) }\end{array}$ & $\begin{array}{l}\text { Chronic } \\
\text { hepatitis B }\end{array}$ & $\begin{array}{l}\text { Total }=57 \\
\text { Cases }=29 \\
\text { Controls }=28\end{array}$ & 6 weeks & $\begin{array}{l}\text { Kuan-Sin-Yin } \\
\text { (seven herb formula, } \\
\text { once daily) }\end{array}$ & $\begin{array}{l}\text { Kuan-Sin-Yin } \\
\text { diluted } 16 \text { times } \\
\text { (seven herb formula, } \\
\text { once daily) }\end{array}$ & $\begin{array}{l}\text { 1. } \text { ALT } \\
\text { Cases }=56.2 \pm 38.4^{* *} \\
\text { Controls }=67.5 \pm 39\end{array}$ \\
\hline $\begin{array}{l}\text { Liu } \\
(2016)\end{array}$ & $\begin{array}{l}\text { Chronic } \\
\text { hepatitis C }\end{array}$ & $\begin{array}{l}\text { Total }=57 \\
\text { Cases }=29 \\
\text { Controls }=28\end{array}$ & 6 weeks & $\begin{array}{l}\text { Kuan-Sin-Yin } \\
\text { (seven herb formula, } \\
\text { once daily) }\end{array}$ & $\begin{array}{l}\text { Kuan-Sin-Yin } \\
\text { diluted } 16 \text { times } \\
\text { (seven herb formula, } \\
\text { once daily) }\end{array}$ & $\begin{array}{l}\text { 1. } \text { ALT } \\
\text { Cases }=74.7 \pm 32.2^{*} \\
\text { Controls }=91.2 \pm 61.4\end{array}$ \\
\hline $\begin{array}{l}\text { Min } \\
(2013)\end{array}$ & $\begin{array}{l}\text { Chronic } \\
\text { hepatitis B }\end{array}$ & $\begin{array}{l}\text { Total }=560 \\
\text { Cases }=280 \\
\text { Controls }=280\end{array}$ & 48 weeks & $\begin{array}{l}\text { Tiaoganjianpihuoxue grain } \\
\text { (13 herb formula, } \\
\text { twice daily + adefovir } \\
\text { (10 mg once daily) }\end{array}$ & $\begin{array}{l}\text { Adefovir (10 mg } \\
\text { once daily) } \\
+ \text { TMC placebo } \\
\text { (twice daily) }\end{array}$ & $\begin{array}{l}\text { 1. } \text { HBV D NA loss } \\
\text { Cases }=105 / 280 \\
\text { Controls }=98 / 279 \\
\text { 2. HBeAg loss } \\
\text { Cases }=83 / 280 \\
\text { Controls }=50 / 280\end{array}$ \\
\hline $\begin{array}{l}\mathrm{Ye} \\
(2016)\end{array}$ & $\begin{array}{l}\text { Chronic } \\
\text { hepatitis B }\end{array}$ & $\begin{array}{l}\text { Total }=368 \\
\text { Cases }=134 \\
\text { Controls }=134\end{array}$ & 48 weeks & $\begin{array}{l}\text { Shuanghu Qinggan Granule } \\
\text { ( } 12 \text { herb formula } 12 \mathrm{~g} \text {, } \\
\text { three times daily)+ } \\
\text { Yigan Yiqi Jieyu Granule } \\
\text { (seven herb formula } 10 \mathrm{~g} \text {, } \\
\text { three times daily)+ } \\
\text { Lamivudine } \\
\text { (100 mg once daily) }\end{array}$ & $\begin{array}{l}\text { Placebo ( } 22 \mathrm{~g} \text { three } \\
\text { times daily)+ } \\
\text { Lamivudine (100 } \mathrm{mg} \\
\text { once daily) }\end{array}$ & $\begin{array}{l}\text { 1. } \text { HBV D NA loss } \\
\text { Cases }=28 / 100 \\
\text { Controls }=17 / 96 \\
\text { 2. } \text { HBeAg loss } \\
\text { Cases }=38 / 100 \\
\text { Controls }=23 / 96 \\
\text { 3. } \text { ALT } \\
\text { Cases }=48.20 \pm 95.06 \\
\text { Controls }=46.70 \pm 56.58\end{array}$ \\
\hline $\begin{array}{l}\text { Youngcai } \\
\text { (2016) }\end{array}$ & $\begin{array}{l}\text { Chronic } \\
\text { hepatitis B }\end{array}$ & $\begin{array}{l}\text { Total }=100 \\
\text { Cases }=50 \\
\text { Controls }=50\end{array}$ & 48 weeks & $\begin{array}{l}\text { Dahuang Whechong capsules } \\
\text { (four capsules twice daily) } \\
\text { +entecavir ( } 0.5 \mathrm{mg} \text { once } \\
\text { daily) }\end{array}$ & $\begin{array}{l}\text { Entecavir ( } 0.5 \mathrm{mg} \\
\text { once daily) }\end{array}$ & $\begin{array}{l}\text { 1. } \text { HBV D NA loss } \\
\text { Cases }=37 / 50 \\
\text { Controls }=34 / 50 \\
\text { 2. } \text { HBeAg loss } \\
\text { Cases }=6 / 50 \\
\text { Controls }=5 / 50 \\
\text { 3. ALT } \\
\text { Cases }=28.7 \pm 14^{*} \\
\text { Controls }=34.98 \pm 25.56^{*}\end{array}$ \\
\hline
\end{tabular}


Herbal Medicine for the Treatment of Viral Hepatitis B and C: A Systematic Review of Randomized Controlled Trials

\begin{tabular}{|c|c|c|c|c|c|c|}
\hline $\begin{array}{l}\text { Zhang-1 } \\
\text { (2004) }\end{array}$ & $\begin{array}{l}\text { Chronic } \\
\text { hepatitis B }\end{array}$ & $\begin{array}{l}\text { Total }=50 \\
\text { Cases }=36 \\
\text { Controls }=14\end{array}$ & 12 weeks & Zhaoyangwan (twice daily) & $\begin{array}{l}\text { Interferon (3 } \mathrm{mU} \\
\text { once daily } \\
\text { intramuscular } \\
\text { injection) }\end{array}$ & $\begin{array}{l}\text { 1. HBV DNA loss } \\
\text { Cases }=16 / 36 \\
\text { Controls }=7 / 14 \\
\text { 2. HBeAg loss } \\
\text { Cases }=18 / 36 \\
\text { Controls }=7 / 14\end{array}$ \\
\hline $\begin{array}{l}\text { Zhang-2 } \\
\text { (2004) }\end{array}$ & $\begin{array}{l}\text { Chronic } \\
\text { hepatitis B }\end{array}$ & $\begin{array}{l}\text { Total }=65 \\
\text { Cases }=40 \\
\text { Controls }=25\end{array}$ & 24 weeks & $\begin{array}{l}\text { Hejie decoction } \\
\text { (eight herb formula, } \\
\text { once daily) }\end{array}$ & $\begin{array}{l}\text { W-med (vitamin } \\
\text { B.C.E. two tablets } \\
\text { three times daily) }\end{array}$ & $\begin{array}{l}\text { 1. } \text { HBV D NA loss } \\
\text { Cases }=0 / 40 \\
\text { Controls }=0 / 25 \\
\text { 2. } \text { HBeAgloss } \\
\text { Cases }=3 / 40 \\
\text { Controls }=1 / 25 \\
\text { 3. } \text { ALT } \\
\text { Cases }=37.01 \pm 9.75^{* *} \\
\text { Controls }=36.01 \pm 9.75^{* *}\end{array}$ \\
\hline $\begin{array}{l}\text { Zhenglong } \\
\text { (2016) }\end{array}$ & $\begin{array}{l}\text { Chronic } \\
\text { hepatitis B }\end{array}$ & $\begin{array}{l}\text { Total }=119 \\
\text { Cases }=69 \\
\text { Controls }=50\end{array}$ & 48 weeks & $\begin{array}{l}\text { Chaiping decoction } \\
\text { (12 herb formula, } \\
\text { twice daily) }\end{array}$ & $\begin{array}{l}\text { Lamivudine (100 mg } \\
\text { once daily) }\end{array}$ & $\begin{array}{l}\text { 1. } \text { HBV DNA loss } \\
\text { Cases }=46 / 69^{* *} \\
\text { Controls }=39 / 50^{* *} \\
\text { 2. ALT } \\
\text { Cases }=30.1 \pm 7.5^{* *} \\
\text { Controls }=48.2 \pm 33.5^{* *}\end{array}$ \\
\hline $\begin{array}{l}\text { Zhou } \\
\text { (2017) }\end{array}$ & $\begin{array}{l}\text { Chronic } \\
\text { hepatitis B }\end{array}$ & $\begin{array}{l}\text { Total }=70 \\
\text { Cases }=35 \\
\text { Controls }=35\end{array}$ & 48 weeks & $\begin{array}{l}\text { Huju Yigan capsules } \\
\text { (five capsules three times } \\
\text { daily) } \\
+ \text { +entecavir ( } 5 \mathrm{mg} \text { once } \\
\text { daily) }\end{array}$ & $\begin{array}{l}\text { Entercavir } \\
\text { (5 mg once daily) }\end{array}$ & $\begin{array}{l}\text { 1. } \text { HBV DNA loss } \\
\text { Cases }=30 / 35 \\
\text { Controls }=16 / 35 \\
\text { 2. } \text { HBeAg loss } \\
\text { Cases }=14 / 35 \\
\text { Controls }=17 / 35 \\
\text { 3. ALT } \\
\text { Cases }=38.27 \pm 7.16^{* *} \\
\text { Controls }=50.13 \pm 9.16^{* *}\end{array}$ \\
\hline $\begin{array}{l}\text { Zhu } \\
\text { (2013) }\end{array}$ & $\begin{array}{l}\text { Chronic } \\
\text { hepatitis B }\end{array}$ & $\begin{array}{l}\text { Total }=271 \\
\text { Cases }=136 \\
\text { Controls }=135\end{array}$ & 52 weeks & $\begin{array}{l}\text { Lingmao formula } \\
\text { (six herb formula } \\
4.5 \mathrm{~g} \text { twice daily) }+ \\
\text { entecavir }(0.5 \mathrm{mg} \text { once } \\
\text { daily) }\end{array}$ & $\begin{array}{l}\text { Placebo } \\
(4.5 \mathrm{~g} \text { twice daily })+ \\
\text { entecavir }(0.5 \mathrm{mg} \\
\text { once daily })\end{array}$ & $\begin{array}{l}\text { 1. } \mathrm{HBeAg} \text { loss } \\
\text { Cases }=31 / 136 \\
\text { Controls }=17 / 135\end{array}$ \\
\hline
\end{tabular}

${ }^{*} \mathrm{p}<0.05,{ }^{* *} \mathrm{p}<0.01$, respectively, vs before treatment in the same group

HCV : hepatitis C virus, ALT : alanine aminotransferase, HBV : hepatitis B virus, HBeAg : hepatitis B e-antigen

1) Study design

Twelve studies investigated hepatitis $\mathrm{B}$, while three studies investigated hepatitis C. Of the 12 studies that investigated hepatitis B, five compared herbal medicine to Western medicine, one compared herbal medicine to a placebo, one compared herbal medicine to diluted herbal medicine, and five compared combination therapies of herbal and Western medicine to Western medicine monotherapy. All studies on hepatitis C compared herbal medicine to placebos.

2) Treatment group and control group

(1) Treatment duration and participants

The duration of treatment varied from 6 to 52 weeks. The total number of participants was 2263, the mean number of participants was 191.1, and the standard deviation for the number of participants 
was 150.2. Of these, the mean number of participants was 94.9 for the experimental group and 86.7 for the control group.
(2) Herbal medicine interventions

The herbal medicines used for the interventions are provided in Table 2.

Table 2. Composition of the Herbal Preparations

\begin{tabular}{|c|c|c|c|}
\hline Study & Preparation name & Formulation & Composition \\
\hline $\begin{array}{l}\text { Batey } \\
(1998)\end{array}$ & $\mathrm{CH}-100$ & Tablet & 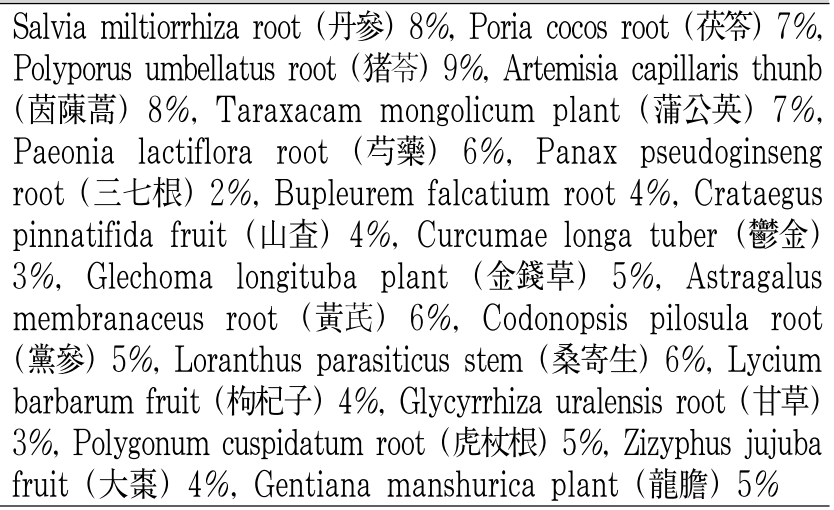 \\
\hline $\begin{array}{l}\text { Chen } \\
(2000)\end{array}$ & Kurorinone & Injection & Matrine extracted from Sophora Flavescens Ait (苦蓼) \\
\hline $\begin{array}{l}\text { Chen } \\
(2005)\end{array}$ & He Jie Tang & Decoction & $\begin{array}{l}\text { Radix Bupleuri (柴胡,) } 10 \mathrm{~g}, \text { Radix Scutellariae (黃芩) } 12 \mathrm{~g} \text {, } \\
\text { Rhizoma Pinelliae (牛夏) } 9 \mathrm{~g} \text {, Radix Codonopsis Pilosulae } \\
\text { (黨參) } 30 \mathrm{~g} \text {, Radix Glycyrrhizae Praeparata (甘草) } 6 \mathrm{~g} \text {, } \\
\text { Fructus Ziziphi Jujubae (酸呆仁) 9 g, Rhizoma Polygoni } \\
\text { Cuspidati (虎杖根) } 30 \mathrm{~g} \text {, Radix Morindae Officinalis (巴戟 } \\
\text { 天) } 8 \mathrm{~g} \text {, Herba Hedyotis Diffusae (白花蛇舌草) } 30 \mathrm{~g}\end{array}$ \\
\hline $\begin{array}{l}\text { Chen } \\
(2017)\end{array}$ & Rong-Yang-Jyh-Gan-Tang & Tablet & $\begin{array}{l}\text { Long-Dan-Xie-Gan-Tang (龍膽寫肝湯) } 3 \mathrm{~g} \text {, Jia-Wei-Xia-Yao-San } \\
\text { (加味逍遥散) } 10 \mathrm{~g} \text {, Dan-Shen (丹參) } 1.5 \mathrm{~g} \text {, Hou-Po (厚朴) } 0.5 \mathrm{~g}\end{array}$ \\
\hline $\begin{array}{c}\mathrm{He} \\
(2013)\end{array}$ & Chinese Herbal Formula & Granules & 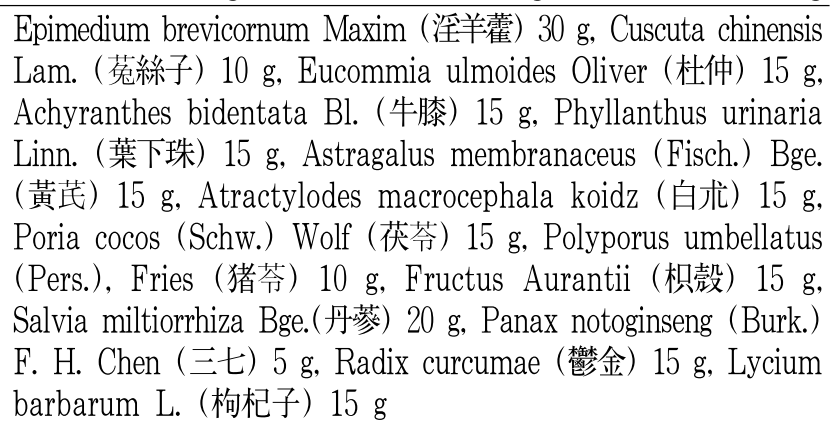 \\
\hline
\end{tabular}




\begin{tabular}{|c|c|c|c|}
\hline $\begin{array}{l}\text { Lee } \\
(2013)\end{array}$ & Kuan-Sin-Yin & Decoction & 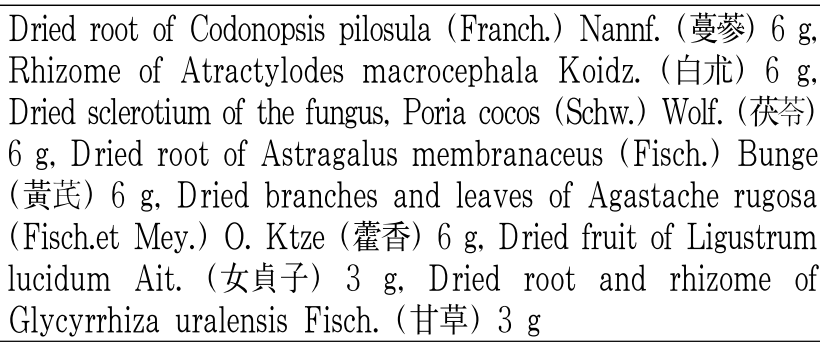 \\
\hline $\begin{array}{c}\operatorname{Liu} \\
(2016)\end{array}$ & Kuan-Sin-Yin & Decoction & $\begin{array}{l}\text { Dried root of Codonopsis pilosula (Franch.) Nannf. (蔓蓼) } \\
6 \mathrm{~g} \text {, Rhizome of Atractylodes macrocephala Koidz. (白术) } 6 \text { g, } \\
\text { Dried sclerotium of the fungus, Poria cocos (Schw.) Wolf. } \\
\text { (茯苓) } 6 \mathrm{~g} \text {, Dried root of Astragalus membranaceus (Fisch.) } \\
\text { Bunge (黃芪) } 6 \text { g, Dried branches and leaves of Agastache } \\
\text { rugosa (Fisch.et Mey.) O. Ktze (藿香) } 6 \text { g, D ried fruit of } \\
\text { Ligustrum lucidum Ait. (女貞子) } 3 \text { g, Dried root and } \\
\text { rhizome of Glycyrrhiza uralensis Fisch. (甘草) } 3 \mathrm{~g}\end{array}$ \\
\hline $\begin{array}{c}\text { Min } \\
(2013) \\
\end{array}$ & $\begin{array}{l}\text { Tiaoganjianpihuoxue grain } \\
\text { /Tiaoganjieduhuashi grain }\end{array}$ & $\begin{array}{c}\text { Not } \\
\text { indicated }\end{array}$ & Not indicated \\
\hline $\begin{array}{c}\mathrm{Ye} \\
(2016)\end{array}$ & $\begin{array}{l}\text { Shuanghu Qinggan Granule } \\
\text { (双虎清肝颗粒) }+ \\
\text { Yigan Yiqi Jieyu Granule } \\
\text { (乙肝益气解有颗粒) }+ \\
\text { lamivudine }\end{array}$ & Granules & $\begin{array}{l}\text { Polygonumcuspidatum (虎杖根), Flos Lonicerae (金銀花), } \\
\text { Hedyotis diffusa (白花蛇舌草), Taraxacum mongolicum (蒲 } \\
\text { 公英), Herba Dendranthematisindici, Herba Violae (紫花地丁), } \\
\text { Trichosanthes kirilowii Maxim (天花粉), Pinellia ternate (牛 } \\
\text { 夏), Rhizoma Coptidis (黃連), Fructus Aurantii Immaturus } \\
\text { (枳殼), Radix Salvia Miltiorrhiza (丹參), Liquorice (甘草), etc. } \\
\text { /Radix Bupleuri (柴胡), Fructus Aurantii (枳殼), Radix } \\
\text { Paeoniae Alba (苟藥), Radix Salvia Miltiorrhiza (丹參), } \\
\text { Radix Astragali (黃芪), Codonopsis Pilosula (蔓䓠), Rhizoma } \\
\text { Coptidis (黃連), etc. }\end{array}$ \\
\hline $\begin{array}{l}\text { Youngcai } \\
\text { (2016) }\end{array}$ & $\begin{array}{l}\text { Dahuang Whechong } \\
\text { (大黄錎虫胶囊) }\end{array}$ & Capsule & Not indicated \\
\hline $\begin{array}{l}\text { Zhang-1 } \\
(2004)\end{array}$ & zhaoyangwan & Decoction & Not indicated \\
\hline $\begin{array}{l}\text { Zhang-2 } \\
\text { (2004) }\end{array}$ & Hejie decoction & Decoction & $\begin{array}{l}\text { Radix Bupleuri (柴胡) } 10 \mathrm{~g} \text {, Radix Scutellariae (黃芩) } 12 \mathrm{~g} \text {, } \\
\text { Rhizoma Pinelliae (半夏) } 9 \mathrm{~g} \text {, Radix Codonopsis Pilosulae } \\
\text { (黨參) } 30 \mathrm{~g} \text {, Radix Glycyrrhizae Praeparata (甘草) } 6 \mathrm{~g} \text {, } \\
\text { Fructus Ziziphi Jujubae (酸呆仁) } 9 \mathrm{~g} \text {, Rhizoma Polygoni } \\
\text { Cuspidati (虎杖根) } 30 \mathrm{~g} \text {, Radix Morindae Officinalis (巴戟 } \\
\text { 天) } 8 \mathrm{~g} \text {, Herba Hedyotis Diffusae (白花蛇舌草) } 30 \mathrm{~g}\end{array}$ \\
\hline
\end{tabular}




\begin{tabular}{|c|c|c|c|}
\hline $\begin{array}{l}\text { Zhenglong } \\
\text { (2016) }\end{array}$ & $\begin{array}{l}\text { Chaiping decoction } \\
\text { (加味柴平汤) }\end{array}$ & Decoction & $\begin{array}{l}\text { Bupleuri Radix (柴胡) } 10 \mathrm{~g} \text {, Scutellariae Radix (黃芩) } 10 \mathrm{~g} \text {, } \\
\text { rhizome of Atractylodes lancea(蒼術) } 10 \mathrm{~g} \text {, Magnolia officinalis } \\
\text { Rehder et Wilson (厚朴) } 10 \mathrm{~g} \text {, Fraxini Cortex (陳皮) } 10 \mathrm{~g} \text {, } \\
\text { Batryticatus Bombyx (僵蚕) } 10 \mathrm{~g} \text {, Curcuma longa Linné } \\
\text { (姜黃) } 10 \mathrm{~g} \text {, Areca catechu Linné (顀榔) } 10 \mathrm{~g} \text {, Salviae } \\
\text { Militiorrhizae Radix (丹蓼) } 20 \mathrm{~g} \text {, Hypericum laxum (Blume) } \\
\text { Koidz. (田基黃) } 30 \mathrm{~g} \text {, Sedum sarmentosum Bunge (垂盆草) } \\
30 \mathrm{~g} \text {, Phyllanth usurinaria L. (叶下珠) } 30 \mathrm{~g}\end{array}$ \\
\hline $\begin{array}{l}\text { Zhou } \\
\text { (2017) }\end{array}$ & $\begin{array}{l}\text { Huju Yigan capsules } \\
\text { (虎驹乙型肝炎胶囊) }\end{array}$ & Capsule & Not indicated \\
\hline $\begin{array}{l}\text { Zhu } \\
\text { (2013) }\end{array}$ & lingmao formula & Granules & $\begin{array}{l}\text { Epimedium brevicornum Maxim. leaf (淫羊藿), Astragalus } \\
\text { membranaceus (Fisch.) Bge. Var. Mongholicus (Bge.) Hsiao. } \\
\text { root (黃芪), Picrorhiza scrophulariiflora Pennell root (胡黃連), } \\
\text { Ranunculus ternatus Thunb root (猫爪草), Ligustrum lucidum } \\
\text { Ait. ripe fruit (白樺), Citrus reticulate Blanco immature fruit peel }\end{array}$ \\
\hline
\end{tabular}

(3) Control group interventions

Generally, antiviral agents were used as the treatment method in the control groups. Entecavir was used in three studies, interferon a and lamivudine were each used in two studies, and adefovir was used in one study. A mixture of vitamin B, vitamin $\mathrm{C}$, and vitamin $\mathrm{E}$ was used in two studies.

\section{3) Outcome measures}

Four outcome measures related to viral hepatitis (hepatitis B virus [HBV] DNA, hepatitis B e-antigen [HBeAg], hepatitis C virus [HCV] RNA, and ALT reduction) were used in the selected studies. HBV DNA reduction was used in 11 studies, $\mathrm{HBeAg}$ reduction was used in nine studies, HCV RNA reduction was used in two studies, and ALT reduction was used in ten studies. A meta-analysis was performed using the rate of HBV DNA, HBeAg, HCV RNA, and ALT reduction as outcome measures.

4) Treatment outcomes

(1) HBV DNA reduction

A total of 11 studies ${ }^{12.14,17-24}$ were included in the HBV DNA reduction assessment. Depending on the type of intervention, the studies were divided into subgroups and assessed. The participants of Chen's study ${ }^{12}$ were divided into mild, moderate, and severe groups, and the outcome data of Chen's study $^{12}$ were analyzed using only the mild and moderate groups because the severe group was excluded from Chen's study ${ }^{12}$ (Table 3).

Table 3. The Criteria for Group Division in Chen's Study

\begin{tabular}{cccc} 
& Mild & Moderate & Severe \\
\hline ALT $\left(\mathrm{U} \mathrm{l}^{-1}\right)^{*}$ & $\leq 120$ & $121-400$ & $>400$ \\
Bilirubin $\left(\mu \mathrm{mol} \mathrm{l}{ }^{-1}\right)$ & $17.1-34.2$ & $34.3-85.5$ & $\geq 85.6$ \\
Albumin $\left(\mathrm{g} \mathrm{l}^{-1}\right)$ & $\geq 35$ & $34-33$ & $\leq 32$ \\
PTA $(\%)^{* *}$ & $79-71$ & $70-61$ & $60-40$ \\
\hline
\end{tabular}

*Alanine aminotransferase, $\left\langle 40 \mathrm{U} \mathrm{l}^{-1}\right.$ as normal

**prothrombin time activity

(1) Herbal medicine vs Western medicine

Five RCTs ${ }^{11,12,20-22}$ were included. The HBV DNA reduction was significantly lower in the herbal medicine groups than in the Western medicine groups (Fig. 2). Heterogeneity was not detected among the studies $\left(\mathrm{OR}=0.54,95 \% \mathrm{CI}: 0.30\right.$ to $\left.0.96, \mathrm{p}=0.04, \mathrm{I}^{2}=0 \%\right)$. 
Herbal Medicine for the Treatment of Viral Hepatitis B and C: A Systematic Review of Randomized Controlled Trials

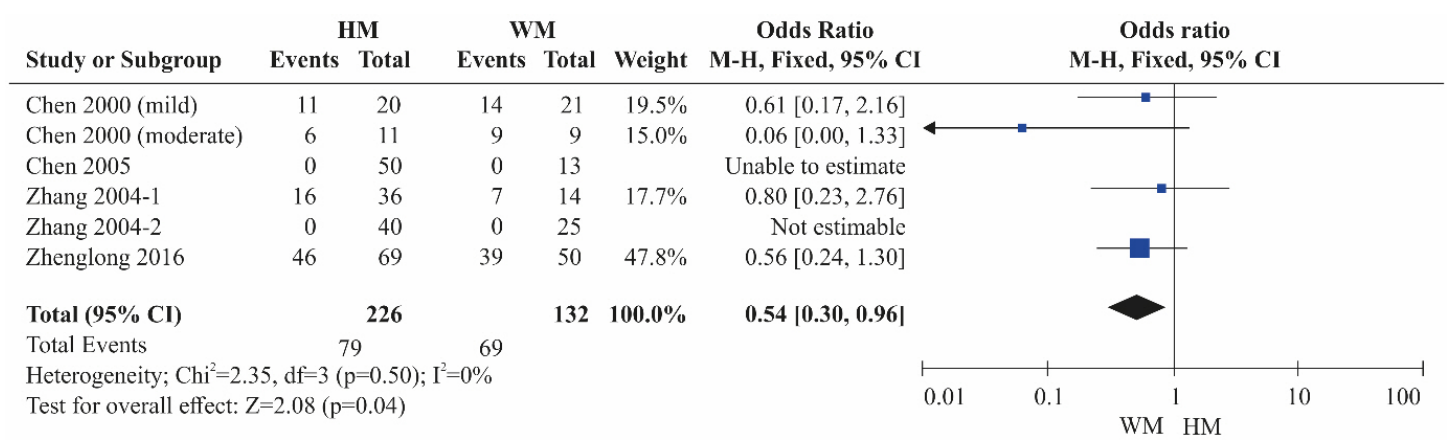

Fig. 2. Results of the meta-analysis for hepatitis B virus DNA reduction (herbal medicine vs Western medicine).

(2) Herbal medicine vs placebo

One study ${ }^{14}$ was included. The HBV DNA reduction was lower in the herbal medicine group than in the control group treated with a placebo (Fig. 3). However, the difference was not statistically significant $(\mathrm{OR}=0.50,95 \% \mathrm{CI}: 0.03$ to $8.04, \mathrm{p}=0.62)$.

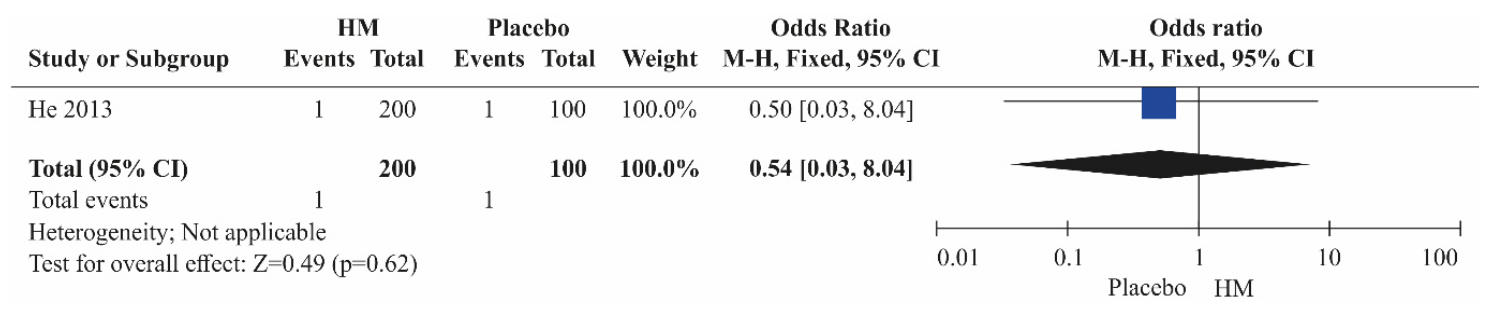

Fig. 3. Results of the meta-analysis for hepatitis B virus DNA reduction (herbal medicine vs placebo).

(3) Herbal medicine+Western medicine vs Western medicine alone

Five RCTs ${ }^{17-19,23,24}$ were included. The HBV DNA reduction was significantly higher in the combination therapy groups (herbal medicine+Western medicine) than in the control groups treated with Western medicine alone (Fig. 4). Heterogeneity was high among the studies $(\mathrm{OR}=1.96,95 \% \mathrm{CI}: 1.12$ to $\left.3.43, \mathrm{p}=0.02, \mathrm{I}^{2}=69 \%\right)$. 


\begin{tabular}{|c|c|c|c|c|c|c|c|c|c|}
\hline \multirow[b]{2}{*}{ Study or Subgroup } & \multicolumn{2}{|c|}{ HM+WM } & \multicolumn{2}{|c|}{ WM } & \multirow[b]{2}{*}{ Weight } & Odds Ratio & \multirow{2}{*}{\multicolumn{2}{|c|}{$\begin{array}{c}\text { Odds ratio } \\
\text { M-H, Random, } \mathbf{9 5 \%} \text { CI }\end{array}$}} & \\
\hline & Events & Total & Events & Total & & M-H, Random , 95\% CI & & & \\
\hline Min 2013 & 105 & 280 & 98 & 279 & $27.6 \%$ & $1.11[0.78,1.56]$ & & $t$ & \\
\hline Ye 2016 & 28 & 100 & 17 & 96 & $21.1 \%$ & $1.81[0.91,3.57]$ & & & \\
\hline Youngcai 2016 & 37 & 50 & 34 & 50 & $17.7 \%$ & $1.34[0.56,3.19]$ & & & \\
\hline Zhou 2017 & 30 & 35 & 16 & 35 & $13.3 \%$ & $7.13[2.24,22.66]$ & & & \\
\hline Zhu 2013 & 29 & 136 & 12 & 135 & $20.4 \%$ & $2.78[1.35,5.71]$ & & $=$ & \\
\hline Total $(95 \% \mathrm{CI})$ & & 601 & & 595 & $100.0 \%$ & $1.96[1.12,3.43]$ & & & \\
\hline Total Events & 229 & & 172 & & & & & & \\
\hline $\begin{array}{l}\text { Heterogeneity; } \mathrm{Tau}^{2}= \\
\text { Test for overall effect }\end{array}$ & $\begin{array}{l}26 ; \mathrm{Chi}^{2}= \\
\mathrm{Z}=2.36(\mathrm{p}=\end{array}$ & $\begin{array}{l}13.11, \mathrm{~d} \\
=0.02)\end{array}$ & $=4(\mathrm{p}=0$. & $1) ; I^{2}=$ & $69 \%$ & 0.0 & 0.1 & 10 & 100 \\
\hline
\end{tabular}

Fig. 4. Results of the meta-analysis for hepatitis B virus DNA reduction (herbal medicine+Western medicine vs Western medicine).

(2) $\mathrm{HBeAg}$ reduction

Nine studies ${ }^{11,12,17-21,23,24}$ were included in the $\mathrm{HBeAg}$ reduction assessment. The studies were divided into subgroups according to the type of intervention and assessed. Chen's study ${ }^{12}$ was analyzed in the same manner as in the HBV DNA reduction assessment.
(1) Herbal medicine vs Western medicine

A total of four RCTs ${ }^{11,1220,21}$ were included. Although the $\mathrm{HBeAg}$ reduction was lower in the herbal medicine groups than in the Western medicine groups, the difference was not statistically significant (Fig. 5). Heterogeneity was not detected among the studies $\left(\mathrm{OR}=0.85,95 \% \mathrm{CI}: 0.42\right.$ to $\left.1.70, \mathrm{p}=0.64, \mathrm{I}^{2}=0 \%\right)$.

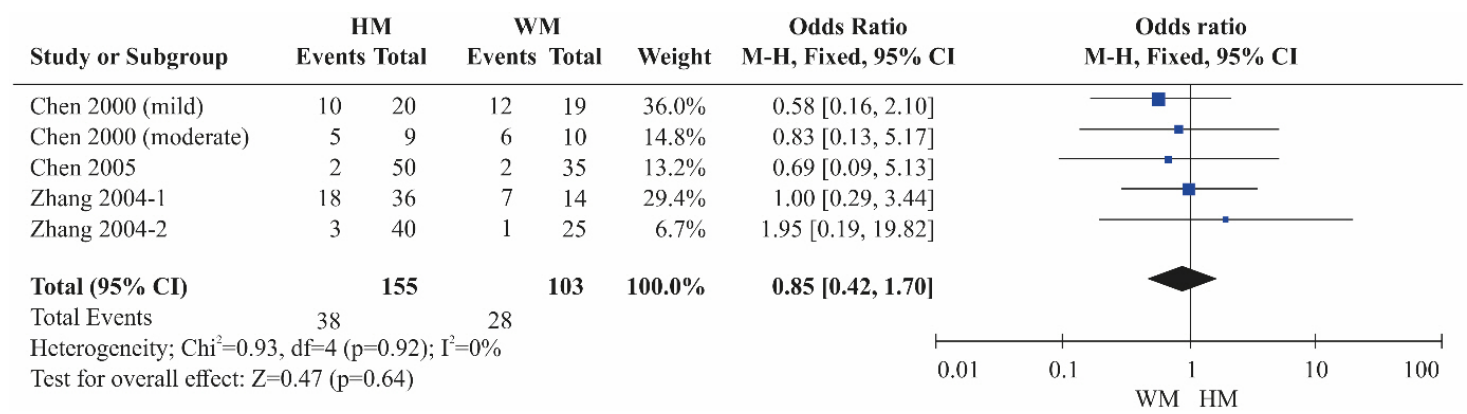

Fig. 5. Results of the meta-analysis for hepatitis B e-antigen reduction (herbal medicine vs Western medicine).

(2) Herbal medicine+Western medicine vs Western medicine alone

Five $\mathrm{RCTs}^{17-19,23,24}$ were included. The $\mathrm{HBeAg}$ reduction was significantly higher in the combination therapy groups (herbal medicine+Western medicine) than in the control groups treated with Western medicine alone (Fig. 6). Heterogeneity was not detected among the studies $(\mathrm{OR}=2.00,95 \% \mathrm{CI}$ : 1.51 to $\left.2.65, \mathrm{p}<0.001, \mathrm{I}^{2}=0 \%\right)$. 
Herbal Medicine for the Treatment of Viral Hepatitis B and C: A Systematic Review of Randomized Controlled Trials

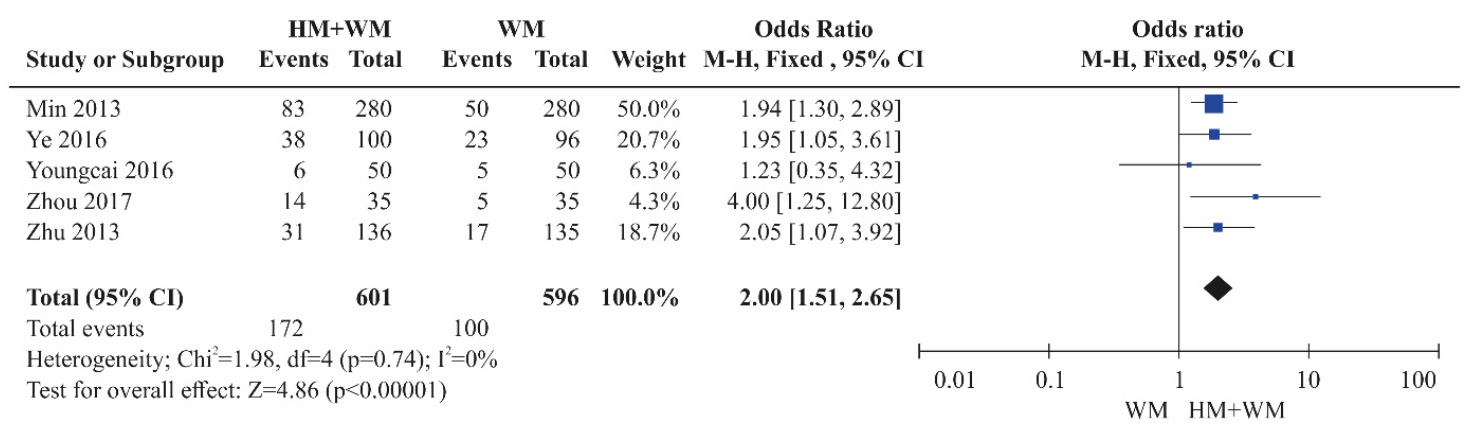

Fig. 6. Results of the meta-analysis for hepatitis B e-antigen loss (herbal medicine+Western medicine vs Western medicine).

(3) HCV RNA reduction

Two studies ${ }^{10,13}$ were included in the HCV RNA reduction assessment. Both studies compared herbal medicine to placebos. The HCV RNA reduction was significantly higher in the herbal medicine groups than in the control groups treated with placebos alone (Fig. 7 ; OR $=3.08,95 \%$ CI: 1.04 to 9.12, $\mathrm{p}=0.04)$.

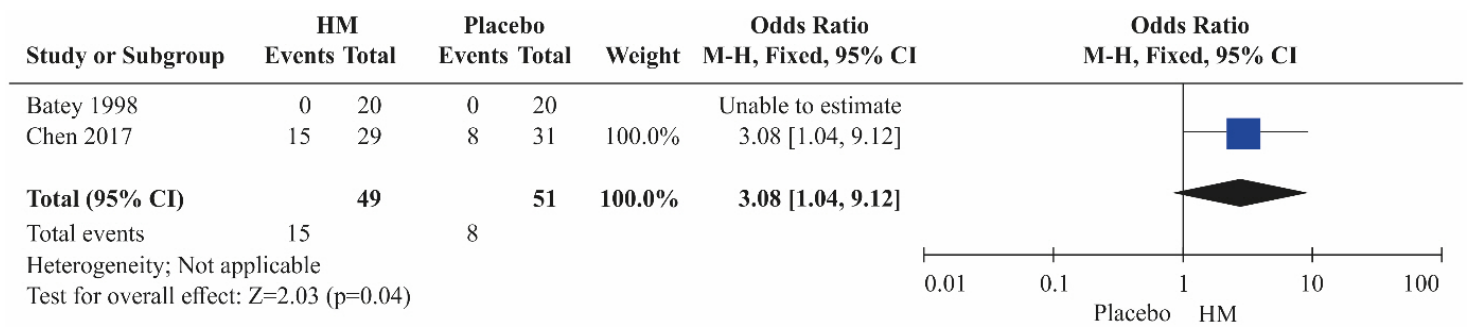

Fig. 7. Results of the meta-analysis for hepatitis $\mathrm{C}$ virus RNA reduction (herbal medicine vs placebo).

(4) ALT

Ten studies ${ }^{10-12,15,16,18,19,21-23}$ were included in the ALT assessment. The studies were divided into subgroups according to the type of intervention and assessed. Chen's study ${ }^{12}$ was analyzed in the same manner as in the HBV DNA reduction assessment.

(1) Herbal medicine vs Western medicine
A total of four RCTs ${ }^{11,12,21,22}$ were included. Although the ALT level was lower in the herbal medicine group than in the control group treated with Western medicine, the difference was not statistically significant (Fig. 8). High heterogeneity was detected among the studies $(\mathrm{MD}=-4.11,95 \%$ CI: -11.15 to $\left.2.92, p=0.25, I^{2}=76 \%\right)$. 


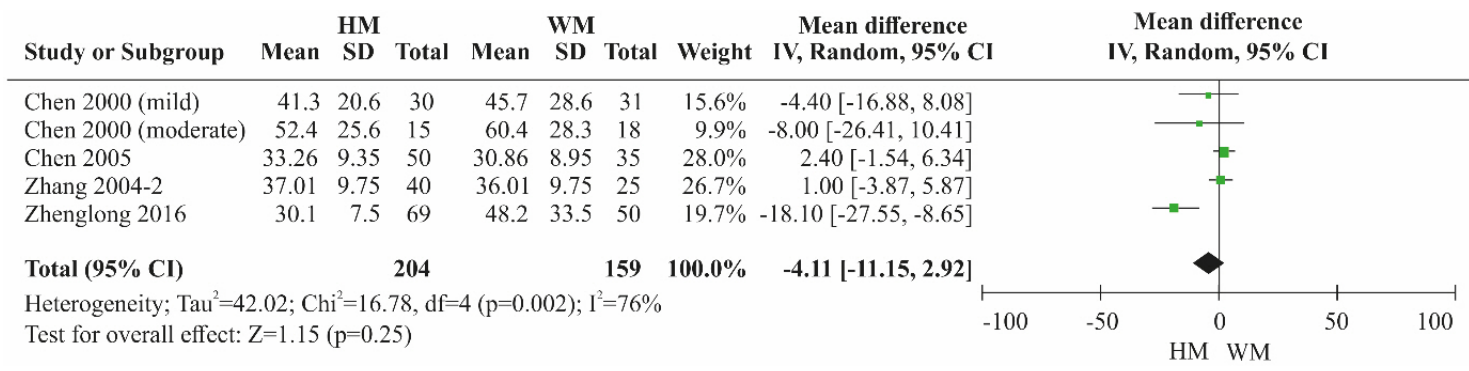

Fig. 8. Results of the meta-analysis for alanine aminotransferase (herbal medicine vs Western medicine).

(2) Herbal medicine vs placebo

A total of two RCTs ${ }^{10,16}$ were included. Although the ALT level was lower in the herbal medicine groups than the control groups treated with placebos, the difference was not statistically significant (Fig. 9). Heterogeneity was not detected among the studies $(\mathrm{MD}=-17.73,95 \% \mathrm{CI}:-38.33$ to $2.87, \mathrm{p}=0.09$, $\left.\mathrm{I}^{2}=0 \%\right)$.

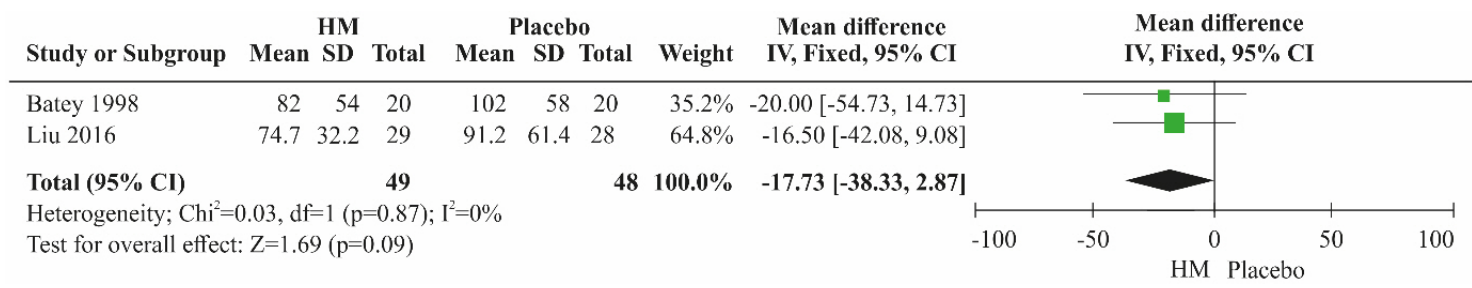

Fig. 9. Results of meta-analysis for alanine aminotransferase (herbal medicine vs placebo).

(3) Herbal medicine vs diluted herbal medicine One $\mathrm{RCT}^{15}$ was included. Although the ALT level was lower in the herbal medicine group than in the control group treated with diluted herbal medicine, the difference was not significant (Fig. 10; $\mathrm{MD}=-11.30,95 \% \mathrm{CI}:-31.40$ to $8.80, \mathrm{p}=0.27$ ).

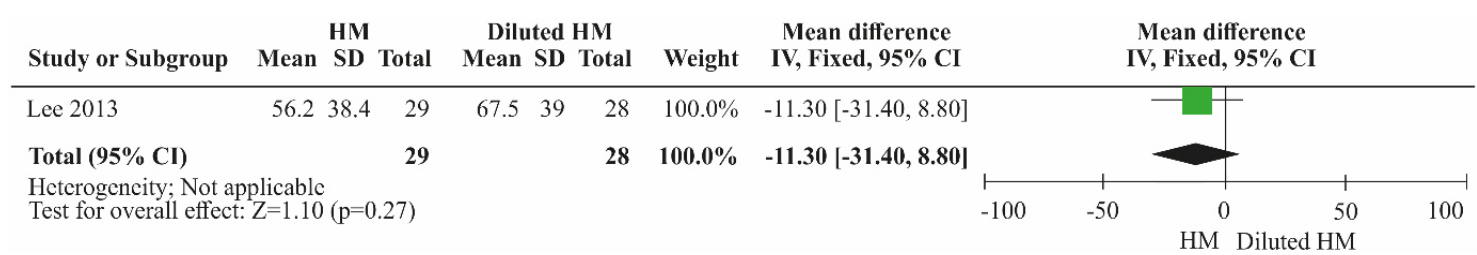

Fig. 10. Results of the meta-analysis for alanine aminotransferase (herbal medicine vs diluted herbal medicine).

(4) Herbal medicine+Western medicine vs Western medicine alone
Three RCTs ${ }^{18,19,23}$ were included. The ALT level was significantly lower in the combination therapy 
Herbal Medicine for the Treatment of Viral Hepatitis B and C: A Systematic Review of Randomized Controlled Trials

groups (herbal medicine+Western medicine) than in among the studies $(\mathrm{MD}=-10.42,95 \% \mathrm{CI}:-13.83$ the control groups treated with Western medicine to $\left.-7.00, p<0.001, I^{2}=36 \%\right)$. alone (Fig. 11). Low heterogeneity was detected

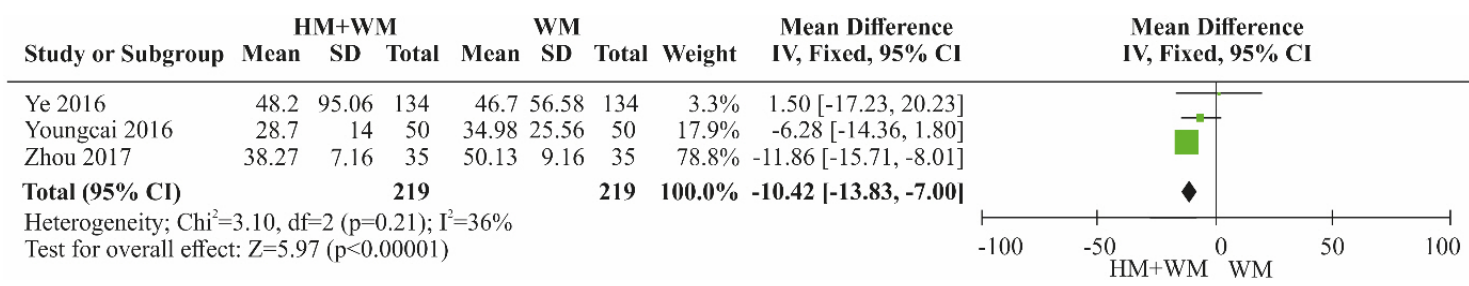

Fig. 11. Results of the meta-analysis for alanine aminotransferase (herbal medicine + Western medicine vs Western medicine).

5) Bias assessment

Risk of bias assessment was performed on the 15 studies selected for the analysis using Cochrane's RoB tool (Fig. 12, Fig. 13). Three studies ${ }^{13.16,24}$ that used tables of random numbers were classified as having a low risk of bias. Onestudy ${ }^{10}$ that used identically-shaped packages with serial numbers and one study ${ }^{15}$ that used independent central randomization were classified as a low risk of bias. Six studies ${ }^{13,14,16-18,24}$ that employed double blinding were classified as a low risk of bias, while three studies $^{12.20,21}$ that compared decoction, capsule, and injection administration methods were classified as having a high risk of bias since blinding was not possible. One study ${ }^{16}$ that employed blinding of the outcome assessor was classified as having a low risk of bias. Thirteen studies ${ }^{10-16.18-22.24}$ that reported all reasons for and numbers of dropout participants or without missing data were classified as a low risk of bias. In the selective reporting domain, 14 studies $^{10.11,13-24}$ that reported the study protocol or all expected outcomes were classified as a low risk of bias. Studies were classified as unclear risk for all other assessment domains if no details were reported.

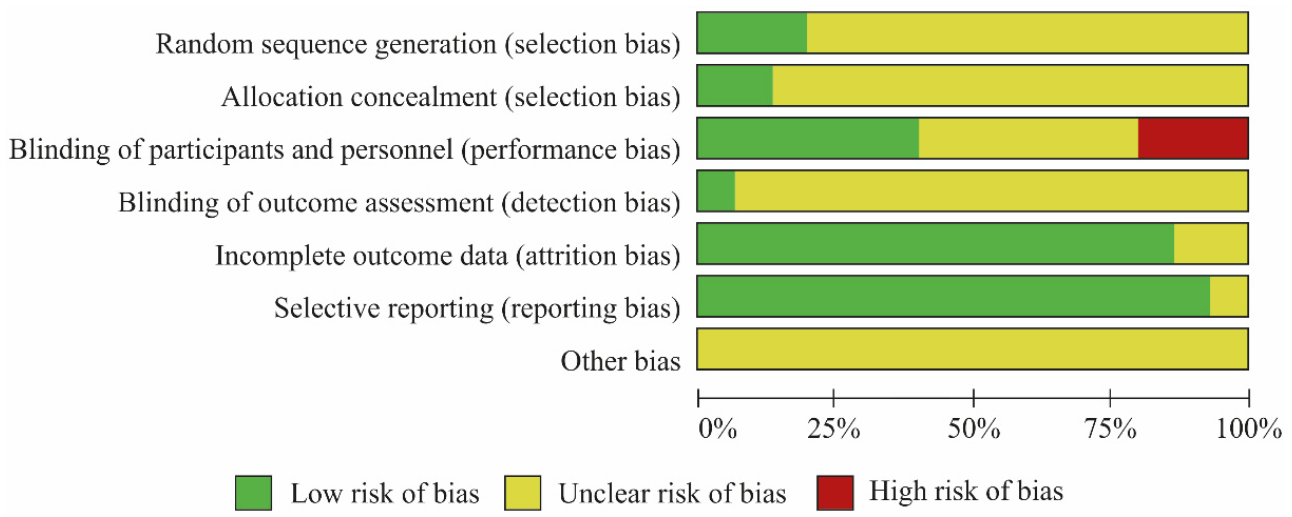

Fig. 12. Risk of bias graph. 


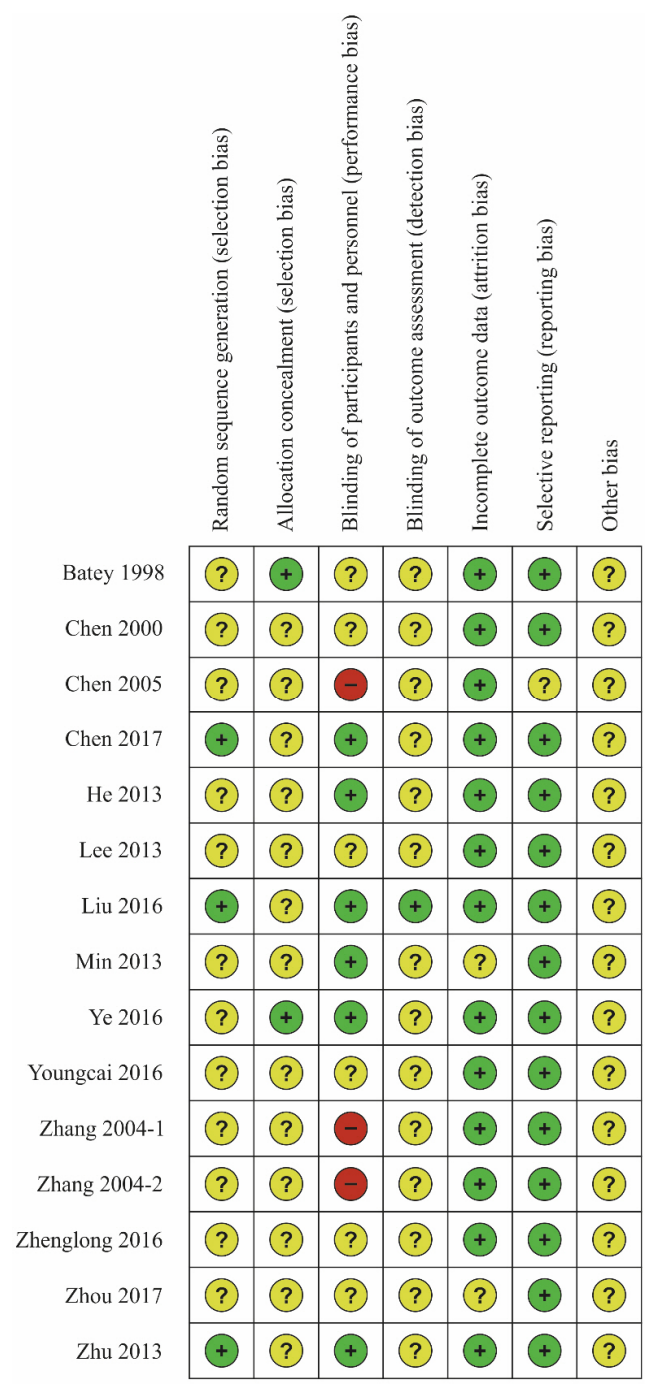

Fig. 13. Risk of bias summary.

6) Publication bias

Examination of the contour-enhanced funnel plot revealed that the plot was visually symmetrical (Fig. 14). In addition, the results of Egger's regression analysis indicated that there was no potential for publication bias $(t=-0.76519, \mathrm{df}=9, \mathrm{p} \text {-value }=0.4637)^{25}$.

7) Safety

Of the 15 studies selected, cases of participant dropout due to the occurrence of serious adverse events were identified in four studies ${ }^{10.14 .18 .24}$. Participants dropped out from the experimental group in three studies $^{10.14 .24}$ and from the control group in two studies $^{18,24}$. Symptoms of adverse events included increased ALT levels, decreased lymphocytes levels, palpitations, and diarrhea.

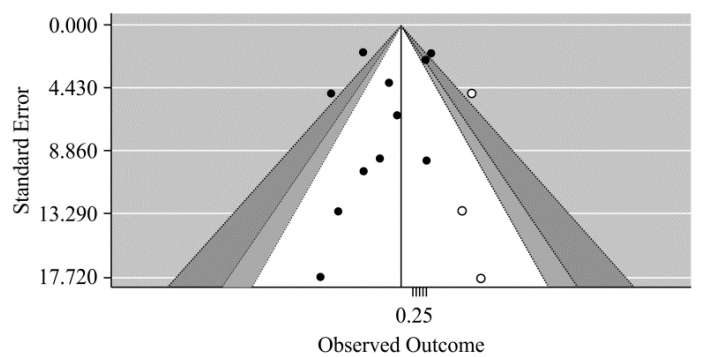

Fig. 14. Contour-enhanced funnel plot.

The funnel plot is centered at 0 , the value under the null hypothesis of no effect. The region outside of the funnel corresponds to $\mathrm{p}$-values of $\langle 0.01$, the dark gray shaded region corresponds to $\mathrm{p}$-values between 0.05 and 0.01 , the gray shaded region corresponds to $\mathrm{p}$-values between 0.10 and 0.05 , and the white region in the middle corresponds to $\mathrm{p}$-values of $>0.10$.

\section{Discussion}

The present study consisted of a systematic review and meta-analysis to investigate the therapeutic effect of herbal medicine on viral hepatitis B and C. The selected studies included RCTs of herbal medicine monotherapy and combination therapy of herbal and Western medicine in patients with viral hepatitis B and C. The therapeutic effect of herbal medicine was assessed in 15 studies using four outcome measures (HBV DNA, HBeAg, HCV RNA, and ALT reduction).

RCTs and meta-analyses regarding herbal medicine treatment of viral hepatitis have not yet been conducted in Korea. With regard to studies in China, 
Herbal Medicine for the Treatment of Viral Hepatitis B and C: A Systematic Review of Randomized Controlled Trials

several meta-analyses have examined the therapeutic effects of herbal medicine treatment on chronic hepatitis $C^{26.27}$, HBV-relatedlivercirrhosis ${ }^{28.29}$, and HBV carriers ${ }^{30}$. One study on the therapeutic effect of herbal medicine on hepatitis $\mathrm{C}$ found that combination therapy of herbal medicine and interferon-a resulted in a higher sustained virologic response (SVR) than did herbal medicine monotherapy (49\% vs $33 \%$, relative risk $1.52 ; 95 \%$ CI: 1.23 to 1.89; $\mathrm{p}<0.05)^{27}$. Studies on the therapeutic effect of herbal medicine treatment on HBV-related liver cirrhosis indicated that herbal medicine treatment was more effective in lowering the levels of biochemical factors related to liver cirrhosis than conventional Western medicine treatment ${ }^{28.29}$. Herbal medicine and Western medicine combination therapy was more effective in decreasing $\mathrm{HBeAg}$ seroconversion than Western medicine monotherapy in HBV carriers (relative risk 4.67, 95\% CI: 1.36 to 15.98; $p=0.01 ; p=39 \%)^{30}$. Based on the findings of these previous studies, it was confirmed that herbal medicine treatment may be useful in clinical practice and has a high therapeutic effect, particularly when combined with antiviral agents. However, there were limitations in that the number and quality of the studies included in the meta-analysis were low.

Of the 15 studies included in the present study, 12 were related to chronic hepatitis B and three were related to chronic hepatitis C. Most of the studies were conducted in China. Herbal medicine treatment was provided in various forms, including granules, tablets, decoctions, and injections. In studies wherein the composition of the herbal preparations used in the treatment was described, Glycyrrhiza uralensis was the most commonly used compound (used seven times) followed by Salvia miltiorrhiza BUNGE, Bupleurum falcatum L.,
Scutellaria baicalensis, Astragalus membranaceus, Pinellia ternata Breitenbach, Polygonum cuspidata SIEB. et ZUCC., Polyporus umbellatus FR, and Atractylodesjaponica Koidzumi. Glycyrrhiza uralensis serves to harmonize the ingredients of all drugs ${ }^{31}$, and its use was confirmed in most of the prescriptions. In oriental medicine, "To clear heat and drain dampness" is the primary treatment method for viral hepatitis? and herbal preparations were used. Each of the studies used different herbal preparations, and it is speculated that this was due to modified formula of traditional herbal medicine. In 10 of the studies, Western medicine was used as the intervention in the control group. Western medicine used antiviral agents, such as entecavir, interferon-a, lamivudine, and a defovir, and a vitamin B, vitamin $\mathrm{C}$, and vitamin $\mathrm{E}$ mixture.

The ultimate treatment goals for patients with chronic hepatitis B who are $\mathrm{HBeAg}$-positive or -negative are normal ALT levels, undetectable HBV DNA levels, and a reduction or conversion of serum $\mathrm{HBeAg}^{32}$. The goal of antiviral treatment for hepatitis $C$ is to achieve an SVR, wherein HCV RNA is undetectable in the serum by a sensitive assay at 12 or 24 weeks after the completion of treatment ${ }^{32}$. Thus, the present study examined four outcome measures (HBV DNA, HBeAg, HCV RNA, and ALT reduction) and found that the outcome measures of HBV DNA, HBeAg, HCV RNA, and ALT reduction were used in 11 , nine, two, and 10 studies, respectively.

The results of the meta-analysis indicated that the HBV DNA reduction was significantly lower in the groups treated with herbal medicine alone than in the groups treated with Western medicine. Herbal medicine treatment was also less effective than placebos. A comparison of the therapeutic 
effect of herbal medicine and Western medicine combination therapy to that of Western medicine monotherapy revealed that combination therapy had a significantly greater therapeutic effect than did monotherapy. However, heterogeneity was high among the studies. Although the $\mathrm{HBeAg}$ reduction was lower in the herbal medicine monotherapy groups than in the Western medicine groups, the difference was not statistically significant. A comparison of the therapeutic effect of herbal medicine and Western medicine combination therapy to that of Western medicine monotherapy revealed that the $\mathrm{HBeAg}$ reduction was significantly higher in the combination therapy groups.

A comparison of the therapeutic effect of herbal medicine to that of placebo on HCV RNA reduction revealed that the HCV RNA reduction was significantly higher in the herbal medicine groups than in the control groups treated with placebos. Although the ALT level was lower in the herbal medicine groups than in the three control groups treated with Western medicine, placebos, and diluted herbal medicine, the differences were not statistically significant. Also, herbal medicine and Western medicine combination therapy was significantly more effective in lowering the ALT level than Western medicine monotherapy.

There were no significant difference in the HBV DNA, HBeAg, and ALT reduction between herbal medicine monotherapy and Western medicine monotherapy. However, herbal and Western medicine combination therapy was significantly more effective in achieving HBV DNA, HBeAg, and ALT reduction than was Western medicine monotherapy. Therefore, it would be useful to conduct additional clinical studies comparing herbal medicine and Western medicine combination therapy to Western medicine monotherapy.

\section{v. Conclusions}

The present study performed a systematic review of RCTs to investigate the therapeutic effect of herbal medicine in patients with viral hepatitis B and C. However, this study has several limitations. Bias assessment of the studies was difficult, as most studies did not mention the details required to assess bias. The total number of RCTs included in the study was limited to 15 , and there were only three RCTs on hepatitis $\mathrm{C}$, so the interpretation should be regarded carefully. And this study analyzed papers $p$ to 2018. Now still, there is no RCT using herbal medicine implemented in Korean hepatitis patients. So, a future study with higher standards that addresses this issue is needed.

The results indicated that herbal medicine and Western medicine combination therapy is more effective than Western medicine monotherapy. Currently, most patients with viral hepatitis seek oriental medicine for symptom relief after receiving antiviral therapy. Notably, based on the findings of this study, adjunctive herbal medicine therapy for the treatment of viral hepatitis may be beneficial. This result could be beneficial in increasing the treatment rate of viral hepatitis clinical practice in herbal medicine. This study's findings may serve as the basis for future clinical research designs in Korea.

\section{Acknowledgements}

This work was supported by the National Research Foundation of Korea (NRF) grant funded by the 
Herbal Medicine for the Treatment of Viral Hepatitis B and C: A Systematic Review of Randomized Controlled Trials

Korean government (MSIT) (No. 2018R1A5A2025272).

\section{References}

1. Kasper DL, Fauci AS, Hauser S, Longo D, Jameson JL, Loscalzo J. Harrison's Principles of Internal Medicine. 19th edition. Seoul: McGraw-Hill Professional Publishing; 2017, p. 2877-96.

2. Decker A, Neumann-Haefelin C, Thimme R. Viral hepatitis A-E. Internist (Berl) 2021;62(2):163-74.

3. World Health Organization, 2017. Global Hepatitis Report, 2017. ISBN: 978-92-4-156545-5. Available at: http://apps.who.int/iris/bitstream/handle/10665/ 255017/WHO-HIV-2017.06-eng.pdf.? sequence = 1 . Accessed 14 Nov 2018.

4. Almeida PH, Matielo CEL, Curvelo LA, Rocco RA, Felga G, Della Guardia B, et al. Update on the management and treatment of viral hepatitis. World J Gastroenterol 2021;27(23) :3249-61.

5. Jeong SH. Epidemiology of Hepatitis C Virus Infection in Korea. The Korean Journal of Medicine 2015:88(6) :630-4.

6. Richmond JA, Bailey DE, Patel K, Jezsik JA, Muir A, Lin JR, et al. The use of complementary and alternative medicine by patients with chronic hepatitis C. Complement Ther Clin Pract 2010; 16(3) :124-31.

7. Jeongughanuigwadaehag gangyenaegwahaggyosil. Gangyenaegwahag. Seoul: Nado; 2013 p. 292-8.

8. Huang X, Lin J, Demner-Fushman D. Evaluation of PICO as a knowledge representation for clinical questions. AIMU Annu Symp Proc 2006;2006: 359-63.

9. Kim SY, Park JE, Seo HJ, Seo HS, Son HJ, Sin CM, et al. NECA's guidance for undertaking systematic reviews and meta-analyses for intervention. Seoul: National Evidence-based
Healthcare Collaborating Agency; 2011, p. 141-2.

10. Batey RG, Bensoussan A, Fan YY, Bollipo S, Hossain MA. Preliminary report of a randomized, double-blind placebo-controlled trial of a Chinese herbal medicine preparation $\mathrm{CH}-100$ in the treatment of chronic hepatitis C. $J$ Gastroenterol Hepatol 1998;13(3):244-7.

11. Chen C, Guo SM, Liu B. A randomized controlled trial of kurorinone versus interferon-a2a treatment in patients with chronic hepatitis B. $J$ Viral Hepat 2000;7(3):225-9.

12. Chen ZX, Zhang SJ, Lao SX, Hu HT, Zhang, CY, Guan SH, et al. He Jie Tang in the treatment of chronic hepatitis B patients. World J Gastroenterol 2005;11(42):6638-43.

13. Chen FP, Chang CM, Wu TP, Yang JL, Kung YY, Huang YH, et al. Clinical efficacy of Rong-Yang-Jyh-Gan-Tang on patients with chronic hepatitis C: A double-blinded randomized placebo-controlled crossover study. J Ethnopharmacol $2007 ; 196: 1-8$.

14. He J, Zhou D, Tong G, Xing Y, Chen Y, Zhang $X$, et al. Efficacy and safety of a Chinese herbal formula (invigorating kidney and strengthening spleen) in chronic hepatitis B virus carrier: Results from a multicenter, randomized, double -blind, and placebo-controlled trial. Evid Based Complement Alternat Med 2013;2013:961926.

15. Lee CJ, Cheng CH, Li YH, Liu CY, Hsu CH. A Chinese medicine, Kuan-Sin-Yin decoction, improves liver function in hepatitis B virus carriers: A randomized, controlled study. $J$ Altern Complement Med 2013;19(12):964-73.

16. Liu CY, Ko PH, Yen HR, Cheng CH, Li YH, Liao ZH, et al. The Chinese medicine Kuan-Sin-Yin improves liver function in patients with chronic hepatitis C: A randomised and placebo-controlled 
trial. Complement Ther Med 2016:27:114-22.

17. Min L, Chen X, Ye Y, Zhang Q, Ru S, Li X. Modeling and simulating dynamics of completeand poor-response chronic hepatitis B Chinese patients for adefovir and traditional Chinese medicine plus adefovir therapy. Evid Based Complement Alternat Med 2013;2013:767290.

18. Ye YA, Tian DL, Jiang J, Li J, Chen JJ, Li $\mathrm{ZH}$, et al. Effect of Shuanghu Qinggang ranule and Yigan Yiqi Jieyu granule plus lamivudine on chronic hepatitis B patients: A randomized double-blind placebo-controlled trial. Chin $J$ Integr Med 2016;1-7.

19. YongCai X, GuoXin H, YanZhong P, Jie Z, YingPing L. Clinical effect of Dahyang Zhe Chong capsules combined with entecavir in treatment of chronic hepatitis B patients with liver fibrosis. J Clin Hepatol 2016:32:1502-7.

20. Zhang CP, Tian ZB, Liu XS, Zhao QX, Wu J, Liang YX. Effects of Zhaoyangwanon chronic hepatitis B and posthepatic cirrhosis. World $J$ Gastroenterol 2004;10(2):295-8.

21. Zhang SJ, Chen ZX, Lao SX, Huang BJ. Effect of Hejie decoction on $\mathrm{T}$ cell immune state of chronic hepatitis B patients. World $J$ Gastroenterol 2004;10(10): :1436-9.

22. Ye ZR, Du WX, Wu L. Clinical analysis of modified Chaiping decoction in treating $\mathrm{HBeAg}$ -negative chronic hepatitis B. Zhongguo Zhong Yao Za Zhi 2006;41(20):3875-80.

23. Zhou W. Huju Yigan capsules combined with entecavir for treatment of patients with chronic hepatitis B: Clinical efficacy and influence on serum inflammatory factors. Shi Jie Hua Ren Xiao Hua Za Zhi 2017;25(20): 1882-8.

24. Zhu XJ, Sun XH, Zhou ZH, Liu SQ, Lv H, Li M, et al. Lingmao formula combined with entecavir for $\mathrm{HBeAg}$-positive chronic hepatitis B patients with mildly elevated alanine aminotransferase: A multicenter, randomized, double-blind, placebo -controlled trial. Evid Based Complement Alternat Med 2013;2013:620230.

25. Peters JL, Sutton AJ, Jones DR, Abrams KR, Rushton L. Comparison of Two Methods to Detect Publication Bias in Meta-analysis. JAMA 2006:295(6):676-80.

26. Wang J, Xin S, JinX, Yongqian Cheng, Tao Yan, Song Qing, et al. Meta-analysis of combination therapy of Chinese herbs plus interferon and ribavirin in patients with chronic hepatitis $\mathrm{C}$. Med Sci Monit 2016:22:1817-26.

27. Zhao S, Liu E, Wei K, Lu S, Chu Y, Li Y, et al. Interferon plus Chinese herbs are associated with higher sustained virological response than interferon alone in chronic Hepatitis C: A meta-analysis of randomised trials. Antiviral Res 2011;89(2):156-64.

28. Wang T, Zhou X, Liu H, Wang J, Zhang P, Zhu Y, et al. Fuzheng Huayu capsule as an adjuvant treatment for HBV-related cirrhosis: A systematic review and meta-analysis. Phytother Res 2018:32(5):757-68.

29. Wei F, Lang Y, Gong D, Fan Y. Effect of Dahuang zhechong formula on liver fibrosis in patients with chronic hepatitis B: A metaanalysis. Complement Ther Med 2015:23(1): 129-38.

30. Yang Y, Jiang HY, Shi Y, He JL, Su S, Chen Z. Chinese herbal medicine for carriers of the hepatitis B virus: An updated systematic review and meta-analysis. Pharmazie 2014;69(10): 723-53.

31. Jeongughanuigwadaehag bonchohag gongdonggyojae 
Herbal Medicine for the Treatment of Viral Hepatitis B and C: A Systematic Review of Randomized Controlled Trials

-pyeonchanwiwonhoe. Bonchohag, Seoul: Jeongseonsa;

2011, p. 584-6, 577-81.

32. The Korean Association for the Study of the
Liver. Chronic hepatitis B clinical practice guideline. Seoul: Jin Publishing; 2015, p. 6, 28.

\title{
B형 및 C형 간염에 대한 한약 치료의 효과 - 체계적 고찰 연구
}

\author{
김승모, 이유리, 조나경, 최홍식, 김경순 \\ 대구한의대학교 간계내과학교실
}

\begin{abstract}
초 록
본 연구는 $\mathrm{B}$ 형 및 $\mathrm{C}$ 형 간염에 대한 한약 치료의 효과를 평가하기 위해 무작위 임상연구를 대상으로 체계적 문헌고찰 및 메 타분석을 시행하였다.

검색엔진은 EMBASE, Pubmed, NDSL, KMBASE, KISS, KISTI, Koreamed, Koreantk, Oasis database를 이용하였으며 국 내의 검색 엔진 키워드는 '간염' 또는 '바이러스성간염', '한약', '무작위 배정 임상시험'을, 국외 검색 엔진 키워드는 'hepatitis' or 'viral hepatitis' and 'herbal medicine' or 'traditional chinese medicine' and 'randomized controlled trial'을 이용하였다.

연구 결과 15 개의 무작위배정 임상시험을 선택되었으며, 그 중 통계적으로 유의미한 결과를 나타낸 연구는 한약과 양약 복 합치료군이 양약을 투여한 대조군에 비해 HBV DNA loss에서 높은 효과를 보였다. 한약과 양약 복합치료군이 양약을 투여한 대조군에 비해 $\mathrm{HBeAg}$ loss에서 통계적으로 유의한 효과를 보였으며, 한약과 양약 복합치료군이 양약을 투여한 대조군에 비해 $\mathrm{ALT}$ 가 감소하였다.

본 연구는 $\mathrm{B}$ 형 및 $\mathrm{C}$ 형 간염환자를 대상으로 한약의 효과를 확인하기 위해 기존에 시행된 $\mathrm{RCT}$ 연구를 대상으로 체계적 문 헌고찰을 시행하였으며, 한약과 양약의 복합치료가 양약 단독치료에 비해 치료효과가 더 높은 것으로 나타났다.
\end{abstract}

중심어: 한약, 바이러스간염, 체계적 고찰, 메타분석 